\title{
TRUST EVALUATION MODEL WITH REGARD TO THE ROLE OF ENGINEER IN PUBLIC CONSTRUCTION PROJECTS IN TAIWAN
}

\author{
Wen-Lin Tzeng \\ Engineer Division Army Command Headquarters Ministry of National Defense, Taoyuan, Taiwan, R.O.C., \\ s1342024@cc.ncu.edu.tw \\ John Chien-Chung Li \\ Institute of Construction Management National Central University, Taoyuan, Taiwan, R.O.C.
}

Follow this and additional works at: https://jmstt.ntou.edu.tw/journal

Part of the Civil and Environmental Engineering Commons

\author{
Recommended Citation \\ Tzeng, Wen-Lin and Li, John Chien-Chung (2011) "TRUST EVALUATION MODEL WITH REGARD TO THE ROLE OF \\ ENGINEER IN PUBLIC CONSTRUCTION PROJECTS IN TAIWAN," Journal of Marine Science and Technology: Vol. 19: \\ Iss. 1, Article 2. \\ DOI: $10.51400 / 2709-6998.2132$ \\ Available at: https://jmstt.ntou.edu.tw/journal/vol19/iss1/2 \\ This Research Article is brought to you for free and open access by Journal of Marine Science and Technology. It has been \\ accepted for inclusion in Journal of Marine Science and Technology by an authorized editor of Journal of Marine Science and \\ Technology.
}




\title{
TRUST EVALUATION MODEL WITH REGARD TO THE ROLE OF ENGINEER IN PUBLIC CONSTRUCTION PROJECTS IN TAIWAN
}

\author{
Wen-Lin Tzeng* and John Chien-Chung Li**
}

Key words: trust, engineer, public work, Taiwan.

\begin{abstract}
In view of the client distrust in engineer, in the current context in Taiwan, it is uncommon to employ private engineers for public construction projects. In this study, which analyzed data of the period between 2003 and 2006, a questionnaire was administered to collate the viewpoints of clients, contractors, and architects/engineers (A/Es) involved in public construction projects that employed engineer. The opinions of participants regarding trust factors that influenced client evaluations of engineer were analyzed. Twenty-six trust factors were analyzed via interviews and a literature review. These factors were grouped using the principal component method and the varimax rotation approach. Analytical results indicate that the primary factors affecting the trust in engineer employed in public construction projects in Taiwan may be classified into three categories and eight factors.

Variation among three trust relationships-calculative, relational, and institutional — with regard to trust in the handling of projects was assessed. Analytical results demonstrated the validity of the trust model proposed by Rousseau [18]. The influence of institutional trust exists throughout the length of a project, with any variation being minor. Interactive influences exist between calculative trust and relational trust. These types of trusts fluctuate as a project progresses. The results of this study serve as a reference for managing decision making with regard to ensuring client trust in engineer.
\end{abstract}

\section{INTRODUCTION}

In the period 1970-1990 in Taiwan, numerous major construction projects with huge budgets were undertaken. To attract high-quality domestic and international contractors, the

Paper submitted 11/16/07; revised 02/19/08; accepted 04/25/08. Author for correspondence: Wen-Lin Tzeng (e-mail: s1342024@cc.ncu.edu.tw).

*Engineer Division Army Command Headquarters Ministry of National Defense, Taoyuan, Taiwan, R.O.C.

**Institute of Construction Management National Central University, Taoyuan, Taiwan, R.O.C. government adhered to the conditions laid down by Féderation Internationale des Ingénieures Conseils (FIDIC) for construction contracts. It was anticipated that the best execution results would be obtained by enforcing reasonable contract clauses and ensuring impartial contract performance management.

One major difference between FIDIC contracts and traditional domestic Taiwanese construction contracts is that the former stipulate the employment of an engineer. In early times, the role of engineer was limited to Taiwanese public construction contracts; employees of public entities were often appointed to serve as engineer. During this period, engineer was limited by interference from clients and contractors. Furthermore, contractors faced difficulties in complying with the decisions made by engineers.

Beginning in 2001, the government department responsible for overseeing all public construction projects-the Public Construction Committee of Executive Yuan-formally incorporated the role of engineer into standard contracts for the first time. The engineers' role was shaped according to that delineated in FIDIC contracts (1999 edition). In a standard contract, the engineer manages the contract performance and is not restricted by clients or subordinates. Private architects, professional engineers, and consulting companies (A/Es) were allowed to act as an engineer. Consequently, the engineer plays the impartial role of a third party and can function independent of clients and contractors. However clients of public entities can't completely trust private A/Es as engineer. Therefore, public construction projects employing $\mathrm{A} / \mathrm{Es}$ as engineer are uncommon in Taiwan.

Research by Fukuyama [8] indicates that Chinese, French, and Italian societies typically have low levels of trust. The populations in these nations trust family members, but have little trust in those outside their family circles. Therefore, trust management is essential to employ an engineer as construction project partners in Taiwan.

This study employed Rousseau's model [18] to conduct a trust evaluation for public entities with regard to the employment of private $\mathrm{A} / \mathrm{Es}$ as an engineer. The trust model is based on the theory of inter-organizational trust and to enhance trust management. First, the variables influencing trust are acquired via a literature review and expert interviews. 
Second, a questionnaire-based investigation is conducted on personnel who have participated in standard contracts to analyze the role of engineer. Finally, this study verifies Rousseau's model for trust evaluation.

\section{BACKGROUND}

Moore [16] suggested that partner relationships are managed based on trust. Glagola and Sheedy [9] and Cheung et al. [4] indicated that the British and Americans aggressively employ "partnering" in their construction projects; as a result, confrontations are minimized and execution performance is maximized since all those involved in construction projects work in close coordination.

It is because trust varies across different environments, conditions, and other variables that it is difficult to provide a clear definition for it. Most scholars argue that research on trust should focus on factors that affect the development of trust and those that influence trust once it has been established. Wong and Cheung [21], who investigated the problem of group trust among construction partners (clients, A/Es, contractors) in Hong Kong via a questionnaire, identified the factors affecting trust in a relationship between partners.

Shapiro et al. [19] argued that three types of trust are functional in a relationship between partners: deterrence-based trust, knowledge-based trust, and identification-based trust. Over the course of a project, the three trust types are in a state of continuous change. Adopting Shapiro's three trust types, Lewicki and Bunker [13] classified trust into the following three types: (1) calculative, (2) knowledge-based, and (3) identification-based. Lewicki also deemed that calculative trust evolves to knowledge-based trust and then to identification-based trust when interaction increases. Based on relevant economic literatures, Doney et al. [5, 6] identified five processes for establishing trust within an organization: (1) calculative, (2) predictive, (3) intentional, (4) capable, and (5) transferring.

Given the aforementioned discussion, currently, scholars do not consider the influencing factors of a partner's trust to be unique. They thought that this factor leads to different types of trusts that evolve over time. However, until 1998, scholars had not identified the variation in the status of trust or fluctuations in each trust category. Rousseau et al. [18] conducted a comprehensive survey to establish the initial model of inter-organizational trust. As illustrated in Fig. 1, they modeled three basic types of trusts (calculative, relational, and institutional) based on the importance of each type over the period of project development. The bandwidth given in Fig. 1 shows the importance of these trust types.

In Taiwan, the public entity (client) may hire A/Es as an engineer for construction projects via open tendering procedures. Then, trust between the client and the engineer would develop as the project progressed. Clients closely follow the developments in the variation of trust in $\mathrm{A} / \mathrm{Es}$ and focus on different issues at different times. This partnership trust situa-

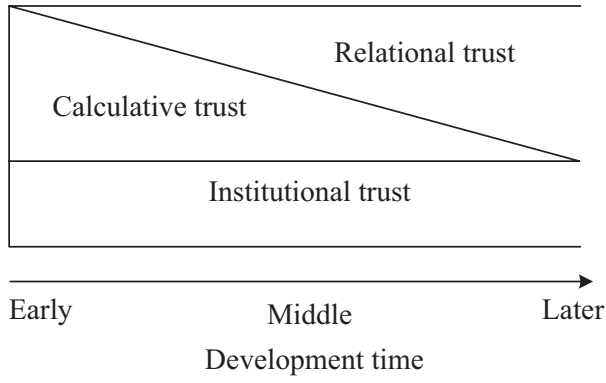

Fig. 1. A model of Trust [18].

tion is in conformity with the situation outlined in Rousseau's model.

\section{RESEARCH APPROACH}

The specific methodology of this research study undertaken in Taiwan follows the concept of the model of Walker [20], which is based on a literature review, expert interviews, and a survey questionnaire. The process included the following:

\section{Literature Review}

The research study began with a review of relevant materials from professional journals, conference papers, refereed publications, and degree theses to capture background information about the evaluation of $\mathrm{A} / \mathrm{Es}$. The objective of conducting a literature review in this study was to determine the variables influencing trust.

\section{Expert Interviews}

The identified factors were scrutinized and verified through a series of face-to-face interviews with a number of selected people possessing eminent experience and those who have been employed as engineers in contracts. These included senior management representatives and site management staffs of clients in Taiwan.

\section{Survey Questionnaire}

A questionnaire was developed to determine the variables influencing trust and to obtain information on the relative importance of different types of trusts during the execution of a project. The draft of the main empirical research questionnaire was taken as a pretest by the participants during the faceto-face interviews. Since no adverse comments were received from the interviewees, the pilot study questionnaire was considered as the final empirical questionnaire for the investigation. Finally, 26 variables that influenced trust were determined, and these constituted the findings of the empirical survey questionnaire. An extract of the final questionnaire is provided in Appendix B, which mentions the variables influencing the level of trust.

\section{Analysis of Survey Results}

Two statistical tools-factor analysis and the AHP (analy- 
Table 1. Characteristics and types of trust.

\begin{tabular}{|c|c|c|}
\hline Category & Characteristic & Content \\
\hline Calculative trust & ability & $\begin{array}{l}\text { - Acknowledgement and trust analyzed and predicted by trustor by collecting and understanding } \\
\text { technology, capability, professional performance and the reputation of a trustee. } \\
\text { - As the amount of information about a trustee a trustor can acquire increases, the accuracy with } \\
\text { which a trustee's actions can be predicted increases. }\end{array}$ \\
\hline Relational trust & benevolence & $\begin{array}{l}\text { - Trust derives from repeated interactions over time between trustor and trustee, this form of trust as } \\
\text { "affective trust." } \\
\text { - Trust continues when the actions of both parties are predictable. }\end{array}$ \\
\hline Institutional trust & integrity & $\begin{array}{l}\text { - Trust based on mechanism codes belong to cultural and social trust. This trust is supported pri- } \\
\text { marily through culture, and is similar to power of law. } \\
\text { - If the institution is excessively rigid, trust between two parties is reduced. }\end{array}$ \\
\hline
\end{tabular}

tical hierarchy process) approach—were used to analyze data from the survey questionnaire. Factor analysis was used to identify the underlying dimensions, whereas the AHP approach was used to calculate the relative weighting of the trust types. Factor analysis was conducted using the SPSS for Windows - a software package that provides a comprehensive range of statistical programs suitable for manipulating an analysis. The weighting calculation was performed using Expert Choice for Windows, a software package.

\section{TRUST INFLUENCE VARIABLES}

This study employs the model of trust evaluation established by Rousseau [18] as its analytical basis. Trust was classified into three types, namely, calculative, relational, and institutional. Mayer [15] identified ability, benevolence, and integrity as three major trust characteristics that can be used to analyze trustworthiness. Rousseau's three types of trusts and Mayer's three trust characteristics are similar. This study uses ability, benevolence, and integrity as the three trust characteristics. Table 1 presents the characteristics and contents of trust.

In their review, Wong and Cheung [21] classified the sources of trust among construction partners into fourteen items; these sources of trust between clients and consultants were roughly categorized under three groups based on performance and permeability of partners, relational bonding between partners, and the system (see Appendix A). The analytical results coincide with the concepts of calculative trust (performance and permeability of partners), relational trust (relational bonding between partners), and institutional trust (system-based trust), which were employed in this study. Ling [14] indicated that a client considers four main factors while selecting a consultant: past performance, price, reputation, and past relationship. Cheung et al. [3] summarized the selection criteria used by 10 different organization/parties and grouped them under similar characteristics. Twelve characteristics were considered applicable to Hong Kong: reputation, technical competence, experience in similar projects, cost control, quality of work, time control, present workload, avail- ability of qualification/experience, approach to time schedule, approach to quality, and design approach.

This study evaluated the trust of a client in private A/Es employed as an engineer. Trust can have several cultural perspectives, depending on the territorial context. The trust variables in this investigation were determined based on Wong and Cheung [21], Ling[14], and Cheung et al. [3]. Moreover, the investigation also involved interviewing construction personnel in Taiwan. Twenty-six variables related to the three types of trusts were selected for evaluating the trust that clients reposed in engineer (Table 2).

\section{DESCRIPTION AND ANALYSIS OF QUESTIONNAIRE}

\section{Analysis of Basic Data}

The Government Procurement Information Publication System (GPIPS) is put across as an important system on the website of the Public Construction Commission (PCC), which is the highest government entity responsible for overlooking all public construction works. The questionnaire survey was framed based on historical GPIPS data from the period between 2003 and 2006 in Taiwan. The selection of data was based on the following criteria: (1) agencies in charge of and involved in contracts employing engineers (or engineering firms), (2) contractors and A/Es involved in awarded contracts valued to be in excess of NT\$50 million (US\$1 N N \$30). Thereafter, questionnaires were designed for (1) directors of public sector entities (clients), (2) managers of contractors, and (3) senior staff at consulting companies or architectural offices.

In total, 293 questionnaires were distributed, out of which 105 completed questionnaires were received. The response rate was $35.8 \%$. Fifty questionnaires were received from clients (42\% of the response rate). About $46 \%$ of those who responded to the questionnaire had prior construction experience exceeding 21 years.

The responses were to be provided on a Likert-type scale. Berdie's (1994) five-point scale was adopted in this study with 
Table 2. Trust influence variables.

\begin{tabular}{|c|c|c|}
\hline Category & Variable & Description \\
\hline \multirow{8}{*}{ Calculative trust } & $\mathrm{C}_{1}$ & Technical competence \\
\hline & $\mathrm{C}_{2}$ & Professionalism of key personnel \\
\hline & $\mathrm{C}_{3}$ & Experience with similar project \\
\hline & $\mathrm{C}_{4}$ & Reputation \\
\hline & $\mathrm{C}_{5}$ & Company stability (such as fluctuation to technology, personnel, financial capability, etc.) \\
\hline & $\mathrm{C}_{6}$ & Past cooperative relationships with client (experience) \\
\hline & $\mathrm{C}_{7}$ & Rationality of service charge \\
\hline & $\mathrm{C}_{8}$ & Knowledge of codes and standards \\
\hline \multirow{14}{*}{ Relational trust } & $\mathrm{R}_{1}$ & Effect of schedule control \\
\hline & $\mathrm{R}_{2}$ & Effect of quality control \\
\hline & $\mathrm{R}_{3}$ & Effect of budget implementation progress \\
\hline & $\mathrm{R}_{4}$ & Ability to troubleshoot issues on site \\
\hline & $\mathrm{R}_{5}$ & Ethical professional behavior \\
\hline & $\mathrm{R}_{6}$ & Client satisfaction (such as interaction with client and service attitudes) \\
\hline & $\mathrm{R}_{7}$ & Level of objectivity \\
\hline & $\mathrm{R}_{8}$ & Ability to coordinate and integrate \\
\hline & $\mathrm{R}_{9}$ & Ability to reduce client cost \\
\hline & $\mathrm{R}_{10}$ & Effect of labor safety control \\
\hline & $\mathrm{R}_{11}$ & Effect of environmental sanitation control \\
\hline & $\mathrm{R}_{12}$ & Number of cases and amount of disputes raised by contractors \\
\hline & $\mathrm{R}_{13}$ & Ability to handle contingencies \\
\hline & $\mathrm{R}_{14}$ & Early warning ability for decision making \\
\hline \multirow{4}{*}{ Institutional trust } & $\mathrm{I}_{1}$ & General trusting tendency of client's organizational culture toward A/E \\
\hline & $\mathrm{I}_{2}$ & Penalty clauses for contractual breaches by engineer as specified in the contract \\
\hline & $\mathrm{I}_{3}$ & Coverage of the A/E's professional insurance liability \\
\hline & $\mathrm{I}_{4}$ & Rules and regulations governing the role of the engineer specified by law \\
\hline
\end{tabular}

the following categorization: (1) extremely important, (2) important, (3) neutral, (4) unimportant, and (5) totally unimportant (see Appendix B).

\section{Analysis of Trust Factors of Questionnaire}

This study employed Cronbach's alpha coefficient (Cronbach's $\alpha$ ) to determine the internal consistency of the Likerttype scale. Pallant [17] suggested that Cronbach's $\alpha$ should be above 0.7 for a scale to be reliable. According to Bryman (1997), Cronbach's $\alpha$ that is greater than 0.8 shows that the scale has high reliability. Guilford [10] believes that Cronbach's $\alpha$ that is greater than 0.7 has high credibility; between 0.7 and 0.35 can be acceptable; and below 0.35 implies that the data from the measured result should be disregarded. In the questionnaire, Cronbach's $\alpha$ for calculative trust, relational trust, and institutional trust were $0.87,0.80$, and 0.57 , respectively. Cronbach's $\alpha$ for the total scale was 0.92 , which is generally considered as highly reliable.

Two statistical measures were also generated by the SPSS to help assess the factorability of the data: Bartlett's test of sphericity and Kaiser-Meyer-Olkin (KMO) measure of sampling adequacy. Bartlett's test of sphericity should be significant $(P<0.05)$ for the factor analysis to be considered as appropriate. Pallant [17] suggested that the KMO index ranges from 0 to 1 , with 0.6 suggested as the minimum value for a reliable factor analysis. Analytical results indicated that for the trust factors of calculative trust, relational trust, and institutional trust, Bartlett's test of sphericity achieved statistical significance. The KMO values for these three types of trusts were $0.705,0.782$, and 0.60 , respectively, none of which were 
Table 3. Correlation between Factors and Variables.

\begin{tabular}{|c|c|c|c|c|c|}
\hline Trust Category & Extract Factor & & Code of Variables & Factor Loading & Cumulative Variance $\%$ \\
\hline \multirow{7}{*}{$\begin{array}{l}\text { Calculative } \\
\text { trust }\end{array}$} & \multirow{4}{*}{$\begin{array}{c}\mathrm{CF}_{1} \\
\text { Professional } \\
\text { Ability }\end{array}$} & $\mathrm{C}_{2}$ & Professionalism of key personnel & 0.886 & \multirow{4}{*}{$45.69 \%$} \\
\hline & & $\mathrm{C}_{3}$ & Experience with similar project & 0.92 & \\
\hline & & $\mathrm{C}_{1}$ & Technical competence & 0.701 & \\
\hline & & $\mathrm{C}_{8}$ & Knowledge of codes and standards & 0.674 & \\
\hline & \multirow{2}{*}{$\begin{array}{l}\quad \mathrm{CF}_{2} \\
\text { Sustainable } \\
\text { Reputation }\end{array}$} & $\mathrm{C}_{5}$ & Company stability & 0.862 & \multirow[b]{2}{*}{$61.99 \%$} \\
\hline & & $\mathrm{C}_{4}$ & Company reputation & 0.759 & \\
\hline & $\begin{array}{c}\mathrm{CF}_{3} \\
\text { Cooperative experience }\end{array}$ & $\mathrm{C}_{6}$ & $\begin{array}{l}\text { Past cooperative relationships with client } \\
\text { (experience) }\end{array}$ & 0.921 & $74.88 \%$ \\
\hline \multirow{14}{*}{ Relational trust } & \multirow{6}{*}{$\begin{array}{c}\mathrm{RF}_{1} \\
\text { Process Representation }\end{array}$} & $\mathrm{R}_{14}$ & Early warning ability for decision making & 0.809 & \multirow{6}{*}{$43.6 \%$} \\
\hline & & $\mathrm{R}_{8}$ & Ability to coordinate and integrate & 0.785 & \\
\hline & & $\mathrm{R}_{13}$ & Ability to handle contingencies & 0.688 & \\
\hline & & $\mathrm{R}_{5}$ & Ethical professional behavior & 0.639 & \\
\hline & & $\mathrm{R}_{9}$ & Ability of reduce client cost & 0.635 & \\
\hline & & $\mathrm{R}_{4}$ & Ability to troubleshoot issues on site & 0.621 & \\
\hline & \multirow{4}{*}{$\begin{array}{l}\quad \mathrm{RF}_{2} \\
\text { Result Representation }\end{array}$} & $\mathrm{R}_{1}$ & Effect of schedule control & 0.870 & \multirow{4}{*}{$55.0 \%$} \\
\hline & & $\mathrm{R}_{6}$ & Client satisfaction & 0.759 & \\
\hline & & $\mathrm{R}_{2}$ & Effect of quality control & 0.753 & \\
\hline & & $\mathrm{R}_{3}$ & Effect of budget implementation progress & 0.595 & \\
\hline & \multirow{2}{*}{$\begin{array}{c}\mathrm{RF}_{3} \\
\text { Performance of environ- } \\
\text { ment and safety }\end{array}$} & $\mathrm{R}_{11}$ & Effect of environmental sanitation control & 0.863 & \multirow[b]{2}{*}{$64.7 \%$} \\
\hline & & $\mathrm{R}_{10}$ & Effect of labor safety control & 0.758 & \\
\hline & \multirow{2}{*}{$\begin{array}{c}\mathrm{RF}_{4} \\
\text { Performance of maintaining } \\
\text { client's benefit }\end{array}$} & $\mathrm{R}_{12}$ & $\begin{array}{l}\text { Number of cases and amount of disputes } \\
\text { raised by contractors }\end{array}$ & 0.811 & \multirow[t]{2}{*}{$72.1 \%$} \\
\hline & & $\mathrm{R}_{7}$ & Level of objectivity & 0.679 & \\
\hline \multirow{4}{*}{$\begin{array}{l}\text { Institutional } \\
\text { trust }\end{array}$} & & $\mathrm{I}_{2}$ & $\begin{array}{l}\text { Penalty clauses for contractual breaches by } \\
\text { engineer as specified in the contract }\end{array}$ & 0.622 & \multirow{3}{*}{$45.1 \%$} \\
\hline & $\begin{array}{c}\qquad \mathrm{IF}_{1} \\
\text { Legal system }\end{array}$ & $\mathrm{I}_{3}$ & $\begin{array}{l}\text { Coverage of the } \mathrm{A} / \mathrm{E} \text { 's professional insur- } \\
\text { ance liability }\end{array}$ & 0.836 & \\
\hline & & $\mathrm{I}_{4}$ & $\begin{array}{l}\text { Rules and regulations governing the role of } \\
\text { the engineer specified by law }\end{array}$ & 0.752 & \\
\hline & $\begin{array}{c}\mathrm{IF}_{2} \\
\text { Culture of Organization }\end{array}$ & $\mathrm{I}_{1}$ & $\begin{array}{l}\text { General trusting tendency of client's or- } \\
\text { ganizational culture toward } \mathrm{A} / \mathrm{E}\end{array}$ & 0.943 & $71.2 \%$ \\
\hline
\end{tabular}

below 0.6 and were thus appropriate to be considered for a factor analysis.

In terms of factor extraction, this study uses the principal component method and selects factors in accordance with eigenvalues greater than 1 , as defined by Kaiser [12]. Major factors were extracted from the variables of different trust types. The cumulative variances of extracted factors were $75 \%, 72 \%$, $71 \%$ for calculative trust, relational trust, and institutional trust, respectively. This result indicates that each extracted factor is representative of a corresponding type of trust.

Since the factor loading matrix is not a simple matrix, it is difficult to identify the correlation between factors and variables. The varimax rotation approach was used to derive the factors from the rotation factor loading matrix and thus identify the meaning of each factor. Furthermore, variables with an absolute factor loading value above 0.5 were selected to explain the extracted factors. Table 3 presents the correlations between factors and variables. 


\section{1) Calculative Trust}

The influence of rationality of service charge (C7) was small and was thus neglected.

Technical competence $(\mathrm{C} 1)$, professionalism of key personnel (C2), experience with similar projects (C3), and knowledge of codes and standards (C8) are related to technical capabilities; these variables can be interpreted as indicative of "professional ability."

Since company stability is an important factor for maintaining or improving the reputation of the company, the variables of reputation (C4) and company stability (C5) can be interpreted as representative of "sustainable reputation."

The cooperative relationship between an engineer and the client in the past (C6) can be interpreted as representative of "cooperative experience."

\section{2) Relational Trust}

Early warning ability for decision making (R14), ability to coordinate and integrate (R8), ability to handle contingencies (R13), ethical professional behavior (R5), ability to reduce client cost (R9), and ability to troubleshoot issues on site (R4) are expected from engineers when a project is being executed. Generally, the performance of an engineer during project execution gradually changes the client's opinion. Therefore, these variables can be interpreted as an indicative of "process representation."

During project execution, the primary goal of project management is to control the schedule, quality, and cost of the project. The project affects the client's degree of satisfaction. Therefore, the four variables of schedule control (R1), client satisfaction (R6), quality control (R2), and budget implement tation progress (R3) can be interpreted as a reflective of "result representation."

The control of environmental pollution and labor safety do not directly affect a project. If, however, there is disregard of environmental norms or occurrence of human injuries, the project may be delayed and a dispute may arise, thereby affecting client trust in the engineer. Therefore, controlling the effects of environmental sanitation control (R11) and the effect of labor safety control (R10) can be interpreted as an indicative of the "environmental and safety performance."

The engineer is the client's representative who manages a project. Excessive disputes with contractors or a lack of sufficient objectivity reduces the client trust in the engineer. The number of disputes raised by contractors (R12) and the level of objectivity (R7) can be interpreted as a representative of the "performance with regard to maintaining client benefits."

\section{3) Institutional Trust}

Penalty clauses for contractual breaches by engineer as specified in the client and A/E service contracts (I2), coverage of the A/E's professional insurance liability (I3), and rules and regulations governing engineer specified by law (I4) are three variables related to contracts and the law. Therefore, in sum, these variables can be interpreted as the "legal system."
The general trusting tendency of the client's organizational culture toward A/E (I1) can be interpreted as an indicative of "organizational culture."

Institutional trust can be treated as supporting trust. It can exist in organizational or social strata, such as a culture, or in legal systems that protect individual rights and property.

\section{Weighting Analysis of Questionnaire Trust Factors}

Rousseau [18] indicated that the influences of calculative trust, relational trust, and institutional trust vary over the course of a construction project. The respondent of the questionnaire selected the relative importance of his/her experiences. A rating scale of 1-9 was used for pair-wise comparisons. The process of comparison yields a relative ranking of priorities of elements with respect to the criterion element to which they were compared. A weighting calculation was performed using Expert Choice, a commercial software developed by Expert Choice, Inc. The weights of calculative trust, relational trust, and institutional trust were obtained to calculate the trust level that a person had in a trustee.

In this study, the initial model of trust by Rousseau et al. [18] (Fig. 1) presents the definitions of trust types for client evaluations of engineer. Relational trust gradually develops after a project is initiated, i.e., no relational trust exists before the start of a project. Calculative trust is a form of acknowledgement trust that decreases due to continuous interaction between the client and engineer. By the time a project is about to end, calculative trust has already been fully replaced by relational trust. Institutional trust, which is a trust based on cultural and social trust, varies slightly during project execution. Therefore, the relative trust weight for different stages of the project is calculated based on the following assumptions.

(1) Trust level is the sum of calculative trust, relational trust, and institutional trust

(2) Trust levels of 0 and 1 denote complete distrust and complete trust, respectively

(3) When construction progress is $0 \%$, relational trust does not exist, whereas when construction progress is $100 \%$, calculative trust does not exist

(4) This study selected the quartile of progress $(25 \%, 50 \%$, and $75 \%$ ) to calculate the relative trust weight for understanding the relative change over the course of the project. The questionnaire answers reflected the opinion of the respondents on the subject of variation in trust in the various quartiles of progress $(25 \%, 50 \%$, and $75 \%)$.

\section{Discussion of Analysis Results}

Analytical results in this study indicate the primary trust factors of public entities that can be used to evaluate private A/Es employed as engineers in Taiwan. The primary trust factors can be classified into three categories (calculative trust, relational trust, and institutional trust), as suggested by Rousseau et al. in 1998. 


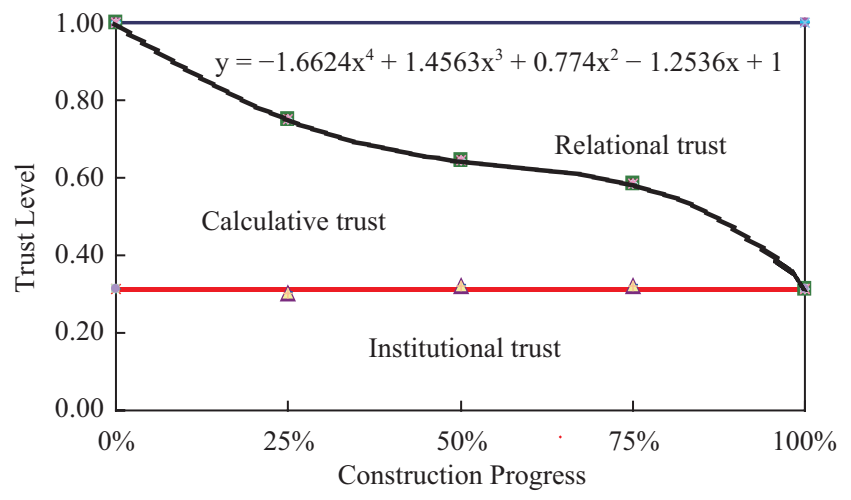

Fig. 2. Relationship of trust weights.

The trust weights for client evaluations of an engineer (Fig. 2) are as follows.

(1) Institutional trust: The weighted values for $25 \%, 50 \%$, and $75 \%$ project progress levels are very close, which supports the assumption that they are constant. The weighted average of 0.31 does not vary as the project progresses.

(2) Calculative and relational trust: The weighted values for the $25 \%, 50 \%$, and $75 \%$ levels (bandwidth in Fig. 2) display a tendency to gradually decrease and increase. That is, with regard to the trust relationship between partners, calculative trust may be more important early on, and the importance of relational trust increases over time.

(3) The curve between calculative trust and relational trust is obtained via a simulation of three known points (when the project progress levels are $25 \%, 50 \%$, and $75 \%$ ) and two assumed points (when the project progress levels are $0 \%$ and $100 \%$ ). The curve tendency of Fig. 2 decreases as the project progresses and roughly coincides with the trust model proposed by Rousseau (Fig. 1).

\section{CONCLUSIONS AND SUGGESTIONS}

Partnership trust between client and engineer (private A/Es) are time sequential. During the initial stages of development of a trust relationship with a partner, calculative trust may be very important. As the project proceeds, relational trust gradually continues to gain in importance. Institutional trust does not vary over time.

It is the A/Es who generate business profits. However, clients must consider the possible moral hazards when employing private A/Es as engineers. Therefore, client trust in engineer must be evaluated to ensure good project performance. To ensure trust management, attention should be paid to how calculative trust and relational trust vary over the course of a project.

- Calculative trust is based on rationality. Reliable and readily available information on professional ability, sustainable reputation, and cooperative experience generates trust.
- Relational trust is rooted in positive expectations resulting from interaction between two partners over time. This is also referred to as affective trust. Relational trust comprises process representation, result representation, environmental and safety performance, and performance in terms of maintaining client benefits.

The trust model that was originally examined and proposed remains at the conceptual stage, and a number of its constituents need to be strengthened and elucidated. Research on quantifying factors and trust models must be carried out as part of further research.

\section{Appendix A-1 Fourteen trust attributes for construction} partnering [5].

\begin{tabular}{l|l}
\hline Item & \multicolumn{1}{|c}{ Trust attribute } \\
\hline$(1)$ & Competence of work (competent) \\
\hline$(2)$ & Problem solving (problem solving) \\
\hline$(3)$ & $\begin{array}{l}\text { Frequency and effectiveness of communication (communi- } \\
\text { cation) }\end{array}$ \\
\hline$(4)$ & Openness and integrity of communication (openness) \\
\hline (5) & Alignment of effort and rewards (alignment) \\
\hline$(6)$ & Effective and sufficient information flow (information flow) \\
\hline (7) & The sense of unity (unity) \\
\hline$(8)$ & Respect and appreciation of the system (respect) \\
\hline (9) & Compatibility (compatibility) \\
\hline$(10)$ & Long-term relationships (long-term relations) \\
\hline$(11)$ & Financial stability (financial) \\
\hline$(12)$ & Reputation (reputation) \\
\hline$(13)$ & Adoption of ADR techniques (adopt ADR) \\
\hline$(14)$ & Contracts and agreements (satisfactory terms) \\
\hline
\end{tabular}

Appendix A-2 Factor score ratings for clients and consultants group and contractors group [5].

\begin{tabular}{|c|c|c|c|c|}
\hline Type & Description & $\begin{array}{l}\text { Factor } \\
\text { score }\end{array}$ & Ranking & $\begin{array}{c}\text { No. of trust } \\
\text { attribute }\end{array}$ \\
\hline \multirow{4}{*}{$\begin{array}{c}\text { Clients and } \\
\text { Consultants } \\
\text { group }\end{array}$} & $\begin{array}{l}\text { Performance of } \\
\text { partners }\end{array}$ & 4.4173 & 3 & $(2)(1)(7)(3)(8)$ \\
\hline & $\begin{array}{l}\text { Permeability of } \\
\text { partners }\end{array}$ & 4.7012 & 2 & $(4)(5)(11)(13)(6)$ \\
\hline & System-based trust & 5.1305 & 1 & $(14)(12)$ \\
\hline & $\begin{array}{l}\text { Relational bonding } \\
\text { between partners }\end{array}$ & 2.8064 & 4 & $(10)(9)$ \\
\hline \multirow{4}{*}{$\begin{array}{l}\text { Contractors } \\
\text { group }\end{array}$} & $\begin{array}{l}\text { Performance and } \\
\text { permeability of } \\
\text { partners }\end{array}$ & 4.9133 & 2 & $(7)(2)(1)(4)(5)(6)(8)$ \\
\hline & System-based trust & 4.9404 & 1 & $(14)(12)(13)$ \\
\hline & $\begin{array}{l}\text { Relational bonding } \\
\text { between partners }\end{array}$ & 4.1905 & 4 & (9) (10) (3) \\
\hline & $\begin{array}{l}\text { Financial stability } \\
\text { of partners }\end{array}$ & 4.6071 & 3 & (11) \\
\hline
\end{tabular}




\section{Appendix B Questionnaire}

\section{Part 1: Investigating the importance of variables influencing trust}

1. I feel the importance of the following factors in terms of the client's calculative trust in an engineer.

Q1 Technical competence

Q2 Company stability (such as fluctuation to technology, personnel, financial capability, etc.) Q3 Experience with similar project

Q4 Past cooperative relationships with client (experience)

Q5 Rationality of service charge

Q6 Professionalism of key personnel

Q7 Knowledge of codes and standards

Q8 Past cooperative relationships with client (experience)

2. I feel the importance of the following factors in terms of the client's relational trust in an engineer.

Q9 Effect of schedule control

Q10 Effect of quality contro

Q11 Level of objectivity

Q12 Effect of budget implementation progress

Q13 Ability to coordinate and integrate

Q14 Ability of reduce client cost

Q15 Client satisfaction (such as interaction with client and service attitudes)

Q16 Ability to troubleshoot issues on site

Q17 Effect of labor safety control

Q18 Effect of environmental sanitation control

Q19 Number of cases and amount of disputes raised by contractors

Q20 Ability to handle contingencies

Q21 Early warning ability for decision making

Q22 Ethical professional behavior

3. I feel the importance of the following factors in terms of the client's institutional trust in an engineer.

Q23 General trusting tendency of client's organizational culture toward A/E

Q24 Penalty clauses for contract breach of the engineer specified in the contract

Q25 Coverage of the A/E's professional insurance liability

Q26 Rules and regulations governing the role of engineer specified by law

\section{Part 2: Investigating the importance variables influencing trust}

In different construction processes, I feel that the relative importance between calculative trust, relational trust, and institutional trust is as follows:

\begin{tabular}{|c|c|c|c|c|c|c|c|c|c|c|c|}
\hline \multirow{2}{*}{$\begin{array}{c}\text { Construction } \\
\text { progress }\end{array}$} & \multirow{2}{*}{ Item A } & \multicolumn{9}{|c|}{ The pair-wise comparison } & \multirow{2}{*}{ Item B } \\
\hline & & 9 & 7 & 5 & 3 & 1 & $1 / 3$ & $1 / 5$ & $1 / 7$ & $1 / 9$ & \\
\hline \multirow{3}{*}{$25 \%$} & calculative trust & & & & & & & & & & relational trust \\
\hline & calculative trust & & & & & & & & & & institutional trust \\
\hline & relational trust & & & & & & & & & & institutional trust \\
\hline \multirow{3}{*}{$50 \%$} & calculative trust & & & & & & & & & & relational trust \\
\hline & calculative trust & & & & & & & & & & institutional trust \\
\hline & relational trust & & & & & & & & & & institutional trust \\
\hline \multirow{3}{*}{$75 \%$} & calculative trust & & & & & & & & & & relational trust \\
\hline & calculative trust & & & & & & & & & & institutional trust \\
\hline & relational trust & & & & & & & & & & institutional trust \\
\hline
\end{tabular}

Extremely Important Important

(4)

\section{(5)}

Neutral Unimpor- Totally

(3)

tant Unimportant
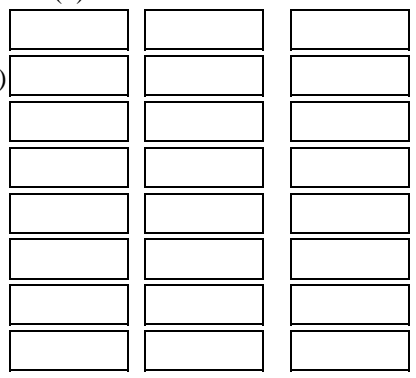

(2) (1)
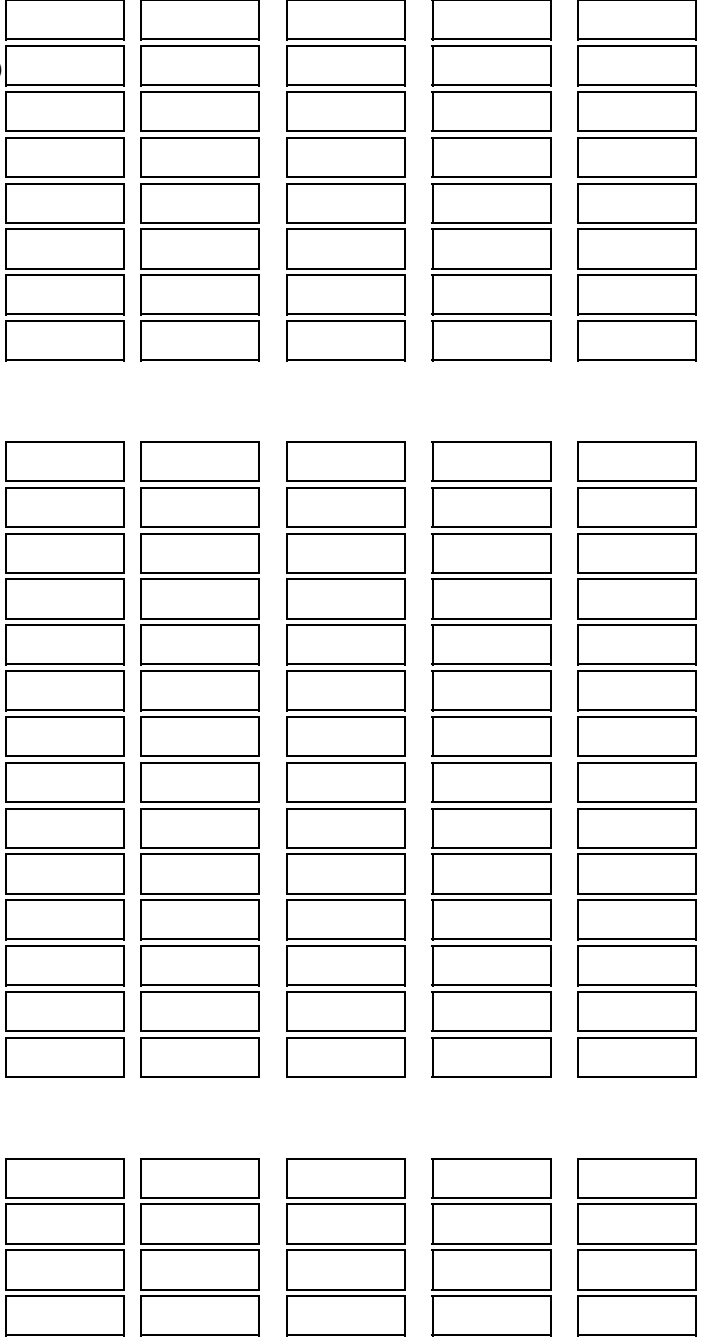

Note: The definitions of weights are as follows:

\begin{tabular}{cc}
\hline Weight & Definition \\
\hline 1 & Equal importance \\
\hline 3 & Weak importance of one over another \\
\hline 5 & Essential or strong importance \\
\hline 7 & Very strong importance \\
\hline 9 & Absolute importance \\
\hline $\begin{array}{c}\text { Reciprocals of } \\
\text { above }\end{array}$ & $\begin{array}{l}\text { If item A has one of the above numbers assigned to } \\
\text { it when compared to item B, then B has the recip- } \\
\text { rocal value when compared with A. }\end{array}$ \\
\hline
\end{tabular}




\section{REFERENCES}

1. Berdie, D. R., "Reassessing the value of high response rates to mail surveys," Marketing Research, Vol. 1, No. 3, pp. 52-64 (1994).

2. Bryman, A. and Cramer, D., Quantitative Data Analysis with SPSS for Windows, London: Routledge (1997).

3. Cheung, F. K. T., Kuen, J. L. F., and Skitmore, M., "Multi-criteria evaluation model for the selection of architectural consultants," Construction Management and Economics, Vol. 20, pp. 569-580 (2002).

4. Cheung, S. O., Ng, T. S. T., Wong, S. P., and Suen, H. C. H., "Behavioral aspects in construction partnering," International Journal of Project Management, Vol. 21, No. 5, pp. 333-343 (2003).

5. Doney, P. M. and Cannon, J. P., "An examination of the nature of trust in buyer-seller relationships," Journal of Marketing, Vol. 61, pp. 35-51 (1997).

6. Doney, P. M., Cannon, J. P., and Mullen, M. R., "Understanding the influence of national culture on the development of trust," Academy of Management Review, Vol. 23, No. 3, pp. 601-620 (1998).

7. Expert Choice, Inc., Expert Choice software (2000 2nd edition) and manual, 4922 Elsworth Ave., Pittsburgh, PA 15213, USA.

8. Fukuyama, F., Trust: The Social Virtues and the Creation of Prosperity, Free Press, New York (1995).

9. Glagola, C. R. and Sheedy, W. M., "Partnering on Defense Contracts, efforts versus the industry average for all other construction," Journal of Construction Engineering and Management, Vol. 128, No. 2, pp. 127-138 (2002).

10. Guieford, J. P., Fundamental Statistics in Psychology and Education, 4th ed., McGraw-Hill, New York (1965).

11. Holt G. D., "Which contraction selection methodology," International
Journal of Project Management, Vol. 16, No. 3, pp. 153-164 (1998).

12. Kaiser, H., "The varimax criterion for analytic rotation in factor analysis," Psychometrica, Vol. 23, pp. 187-200 (1958).

13. Lewicki, R. J. and Bunker, B. B., "Trust in relationships: A model of development and decline," In: Bunker, B. B. and Rubin, J. Z. (Eds.), Conflict, Cooperation, and Justice: Essay Inspired by the Work of Morton Deutsch, Jossey-Bass Publishers, San-Francisco, pp. 133-174 (1996).

14. Ling, Y. Y., "A conceptual model for selection of architects by project managers in Singapore," International Journal of Project Management, Vol. 21, pp. 135-144 (2003)

15. Mayer, R. C., Davis , J. H., and Schoorman, F. D., "An integrative model of organizational trust," Academy of Management Review, Vol. 20, No. 3 , pp. 709-734 (1995).

16. Moore, M., Commercial Relationship, Tudor Business Publishing, UK (1999).

17. Pallant, J., SPSS Survival Manual: A Step-by-Step Guide to Data Analysis Using SPSS for Windows (Version10), Crow Nest, N.S.W. (2001).

18. Rousseau, D. M., Sitkin, S. B., and Butt, R. S., "Not so different after all: A cross-discipline view of trust," Academy of Management Review, Vol. 23, No. 3, pp. 393-404 (1998).

19. Shapiro, D., Sheppard, B. H., and Cheraskin, L., "Business on a handshake," Negotiation Journal, Vol. 8, No. 4, pp. 365-377 (1992).

20. Walker, D. H. T., "Choosing an appropriate research methodology," Construction Management and Economics, Vol. 15, No. 2, pp. 149-159 (1997).

21. Wong, P. S. P. and Cheung, S. O., "Trust in construction partnering: views from parties of the partnering dance," International Journal of Project Management, Vol. 22, No. 6, pp. 437-446 (2004). 